\title{
Genetic parameters affecting 180-days standardised milk yield, test-day milk yield and lactation length in Spanish Assaf (Assaf.E) dairy sheep
}

\author{
J.P. Gutiérrez ${ }^{\mathrm{a}, *}$, E. Legaz ${ }^{\text {b }}$, F. Goyache ${ }^{\mathrm{c}}$ \\ a Dpto. de Producción Animal, Facultad de Veterinaria, Universidad Complutense, E-28040 Madrid, Spain \\ ${ }^{\mathrm{b}}$ Castellana de Ganaderos Sociedad Cooperativa, Campo Real, 28510 Madrid, Spain \\ c SERIDA-Somió, C/ Camino de los Claveles 604, E-33203 Gijón (Asturias), Spain
}

Received 17 January 2006; received in revised form 13 March 2006; accepted 28 March 2006

Available online 2 May 2006

\begin{abstract}
A total of 42,197 records of test-day milk yield (TDY) and 7654 lactations from 3854 individuals belonging to the Spanish Assaf (Assaf.E) breed were analysed using univariate and multivariate models to estimate genetic parameters affecting TDY, total milk yield standardised to 180 days ( $\mathrm{MY}_{180}$ ) and lactation length (LL) in order to asses their possibilities of use in the selection scheme of the Assaf.E population. Estimates of $h^{2}$ were, in general, on the lower limit of those usually reported for the three analysed traits. Estimates of heritability for $\mathrm{MY}_{180}$ varied from 0.131 to 0.177 . Estimates of $h^{2}$ for LL and TDY were consistent regardless the estimation model being of, roughly, $5 \%$ and $10 \%$, respectively. The estimates for the permanent environmental effect $\left(c^{2}\right)$ of TDY were consistently the same $(0.27-0.28)$ regardless the fitted model whilst they showed large differences for LL and MY 180 . Genetic correlations were always positive and high ranging from 0.792 for the pair LL-TDY to 0.999 for the pair MY 180 -TDY. Correlations between permanent environmental effects were even higher ranging from 0.932 for the pair LL-MY 180 and 0.999 for the pair $\mathrm{MY}_{180}$-TDY. The advantages of using TDY as selection criterion in the Assaf.E improvement scheme are discussed.
\end{abstract}

(C) 2006 Elsevier B.V. All rights reserved.

Keywords: Sheep; Variance components; Test-day model; Assaf.E; Milk traits

\section{Introduction}

The Assaf breed was formed in 1955 in Israel by crossing the East Friesian (Milchschaf) with the Awassi breed (Goot, 1986). Assaf individuals were introduced for the first time in Spain in 1977. The expansion of the breed has been done basically by the male-mediated absorption of Spanish native dairy sheep breeds such as

\footnotetext{
* Corresponding author. Tel.: +34 91394 3767; fax: +34 913943767 .

E-mail address: gutgar@vet.ucm.es (J.P. Gutiérrez).
}

Castellana, Churra or Manchega. Ugarte et al. (2001) estimated that $45 \%$ of the roughly 5 million head of sheep exploited for dairy in Spain are foreign breeds (mainly Assaf, Awassi and Lacaune) or crosses. Ugarte et al. (2002) reported that at least 410,000 Assaf heads are grouped in different productive-commercial organisations in Spain and, roughly, 86,000 are under different dairy recording schemes.

A number of dairy recording schemes have been developed in Spain based on Assaf.E individuals focused mainly to management improvement but also for selection (Jiménez and Jurado, 2005; Gutiérrez and Legaz, 2004). From them that implemented by the Cooperative 
Castellana de Ganaderos, included a sire selection program and the publication of a catalogue with the estimated breeding values of the Artificial Insemination sires for 180-days standardised milk yield. Recently the Spanish Ministry of Agriculture has recognised the Spanish Assaf (Assaf.E) flockbook and, the breeders association (ASSAF.E) is interested in the implementation of a national selection scheme. To do this, two major tasks should be settled: (a) to obtain a good genetic connectedness among flocks; and (b) to decide the traits defining the selection goal.

The aim of this paper was to estimate the genetic parameters for 180-days standardised milk yield $\left(\mathrm{MY}_{180}\right)$, test-day milk yield (TDY) and lactation length (LL) using a sample of Assaf.E flocks included in the dairy recording scheme of Castellana de Ganaderos. From the results of the present analysis recommendations on the selection goal for the Assaf.E breed can be given.

\section{Materials and methods}

Production data and pedigree information were obtained from the performance recording database managed by the Cooperative Castellana de Ganaderos. Milking in the Assaf.E flocks is usually carried out twice a day (in the morning and in the afternoon). Test was carried out using the alternative a.m.-p.m. recording scheme at monthly intervals beginning at least 3 days after weaning, being the suckling period of, approximately, 6 weeks. Six test-day records per lactation were obtained. However, lactations with only the first 4 or 5 test days were used in the present analysis. Although dairy recording scheme involved 32 farms, only 19 flocks connected by artificial insemination, located mainly in Madrid and Northern Castilian, were considered for the present analysis. These flocks are representative of the Spanish Assaf population, which have an average flock size of about 500 individuals. Initial database consisted of 30,064 lactations from 16,603 individuals. Animals with identification errors or ambiguous birth dates were eliminated. After editing a total of 7654 lactations from 3854 individuals were available. Database included a total of 42,197 records of test-day milk yield (TDY). Lactation lengths (LL) were computed as the interval between the lambing date and the last test-day date plus 14 days (Barillet, 1985). Total milk yield was standardised to 180 days $\left(\mathrm{MY}_{180}\right)$. The $\mathrm{MY}_{180}$ records were calculated from a set of test-day records taken at monthly intervals following Fleischman's method (Barillet, 1985).

The structure of the analysed records is summarised in Table 1. The analysed database included a total of
Table 1

Structure of data used for the estimation of genetic parameters for 180 days adjusted milk production ( $\mathrm{MY}_{180}$ ), test-day milk yield (TDY) and lactation length (LL) in the Assaf.E breed. The corresponding $\mathrm{MY}_{180}$, TDY and LL statistics are expressed in $\mathrm{kg}$, $\mathrm{mg}$ and days, respectively

\begin{tabular}{lrrr}
\hline Structure of data & MY $_{180}$ & \multicolumn{1}{c}{ TDY } & \multicolumn{1}{c}{ LL } \\
\hline Number of records & 7654 & 42197 & 7654 \\
Animals with record & 3854 & 3854 & 3854 \\
Number of rams & 170 & 170 & 170 \\
Number of dams without records & 147 & 147 & 147 \\
Number of dams with own record as & 1593 & 1593 & 1593 \\
$\quad$ well & 4491 & 4491 & 4491 \\
Total number of animals & 165 & 165 & 165 \\
Rams with progeny in data & 1714 & 1714 & 1714 \\
Ewes with progeny in data & 1593 & 1593 & 1593 \\
Ewes with record and offspring & 19 & 19 & 19 \\
Flocks (levels) & 12 & 12 & 12 \\
Months (levels) & 10 & 10 & 10 \\
Years (levels) (1994-2003) & 4 & 4 & 4 \\
Lambing number (levels) (1, 2, 3, & & & \\
$\quad$ more than three lambs) & 45 & & 45 \\
Days from calving to first test-day & & & \\
$\quad$ (levels) (from the day 31 to the day & & & \\
$\quad$ 75) & & 200 & \\
Days from calving to test-day (levels) & & & \\
$\quad$ (from the day 31 to the day 230) & & & \\
Lactation length as linear covariate & 1 & & \\
$\quad$ Mean & 431.6 & 1660.5 & 199.5 \\
Standard deviation & 164.4 & 1044.1 & 27.1 \\
\hline
\end{tabular}

4491 animals, of which 170 were rams and 1740 dams. A total of 165 sires and 1714 dams had progeny in the data. The number of dams with their own record as well was 1593 . The analysed dataset included 29,138 damoffspring record pairs including all the traits. The average number of progeny records per ram was 146.9. Given that flocks were selected for the analysis according to their connection, a wide use of artificial insemination is present in the data set.

Genetic parameters were estimated via univariate or multivariate REML procedure applied to a mixed linear model. All runs were carried out using the DF-REML program (Meyer, 1998). According to previous analysis (Gutiérrez and Legaz, 2004) the fitted models included the following fixed effects trait: flock, month and year of milking, number of lambing and interval from lambing to test-day date (200 levels, from the day 31 to the day 230) for TDY; flock, month and year of lambing, interval from lambing to the first test-day date (45 levels, from the day 31 to the day 75) and number of lambing for LL; these same effects and the proper LL as a covariate were the fixed effects adjusted to MY 180 . Since prolificacy was not recorded without uncertainty the effect of the number of lambs suckled before weaning, which is over 
1.5 per lambing in the Assaf population, was not included in the fitted models. The structure of the analysed data set is described in Table 1. As regards random effects, two different models were defined:

- Model 1: Univariate animal model including the additive genetic effect (u), the animal permanent environment (c) and the residual (e), with the additive genetic effect (u) being the only random effect dependent on the relationship matrix. Matrix notation of the sets of mixed model equations to be solved is $\mathbf{y}=\mathbf{X b}+\mathbf{Z u}+\mathbf{W p}+\mathbf{e}$, with:

$$
\left(\begin{array}{c}
\mathbf{y} \\
\mathbf{u} \\
\mathbf{p} \\
\mathbf{e}
\end{array}\right) \approx N\left(\left[\begin{array}{c}
\mathbf{X b} \\
0 \\
0 \\
0
\end{array}\right],\left[\begin{array}{llll}
\mathbf{V} & \mathbf{Z G} & \mathbf{W P} & \mathbf{R} \\
\mathbf{G Z \prime} & \mathbf{G} & 0 & 0 \\
\mathbf{P W} \prime & 0 & \mathbf{P} & 0 \\
\mathbf{R} & 0 & 0 & \mathbf{R}
\end{array}\right]\right)
$$

where $\mathbf{V}=\mathbf{Z G Z} \mathbf{Z}^{\prime}+\mathbf{W} \mathbf{P} \mathbf{W}^{\prime}+\mathbf{R}, \mathbf{G}=\mathbf{A} \sigma_{\mathrm{u}}^{2}, \mathbf{P}=\mathbf{I}_{\mathrm{p}} \sigma_{\mathrm{p}}^{2}$ and $\mathbf{R}=\mathbf{I}_{\mathrm{e}} \sigma_{\mathrm{e}}^{2}, \mathbf{y}$ the vector of observations, $\mathbf{X}$ the incidence matrix of fixed effects, $\mathbf{Z}$ the incidence matrix of animal effect, $\mathbf{W}$ the incidence matrix of permanent environmental effect, $\mathbf{b}$ the vector of unknown parameters for fixed effect, $\mathbf{u}$ the vector of unknown parameters for additive genetic effect, $\mathbf{p}$ the vector of unknown parameters for permanent environmental effect, $\mathbf{e}$ the vector of residuals, $\mathbf{I}_{\mathbf{e}}$ the identity matrix of equal order to the number of records, $\mathbf{I}_{\mathbf{p}}$ the identity matrix of equal order to the number of sheep with milking records, A the numerator relationship matrix, $\sigma_{\mathrm{u}}^{2}$ the direct genetic variance, $\sigma_{\mathrm{p}}^{2}$ the permanent environmental variance and $\sigma_{\mathrm{e}}^{2}$ is the error variance.

- Model 2: multivariate animal model, where the three production traits were jointly analysed, including the additive genetic effect, the permanent environmental effect and the residual as random effects in the model for each trait besides the covariance between either direct genetic $\left(\operatorname{cov}_{\mathrm{uu}}\right)$ and permanent environmental $\left(\operatorname{cov}_{\mathrm{cc}}\right)$ effects. Matrix notation of the sets of mixed model equations to be solved is $\mathbf{y}=\mathbf{X b}+\mathbf{Z u}+\mathbf{W} \mathbf{p}+\mathbf{e}$, with:

$$
\left(\begin{array}{l}
\mathbf{y} \\
\mathbf{u} \\
\mathbf{p} \\
\mathbf{e}
\end{array}\right) \approx N\left(\left[\begin{array}{c}
\mathbf{X b} \\
0 \\
0 \\
0
\end{array}\right],\left[\begin{array}{llll}
\mathbf{V} & \mathbf{Z G} & \mathbf{W P} & \mathbf{R} \\
\mathbf{G Z \prime} & \mathbf{G} & 0 & 0 \\
\mathbf{P W} \prime & 0 & \mathbf{P} & 0 \\
\mathbf{R} & 0 & 0 & \mathbf{R}
\end{array}\right]\right)
$$

where $\quad \mathbf{V}=\mathbf{Z G Z}+\mathbf{W} \mathbf{P} \mathbf{W}^{\prime}+\mathbf{R}, \quad \mathbf{G}=\mathbf{A} \otimes \mathbf{G}_{0}$, $\mathbf{P}=\mathbf{I}_{\mathbf{p}} \otimes \mathbf{P}_{0}, \quad \mathbf{R}=\mathbf{I}_{\mathbf{e}} \otimes \mathbf{R}_{0}, \quad \mathbf{y}$ the vector of obser- vations, $\mathbf{X}$ the incidence matrix of fixed effects, $\mathbf{Z}$ the incidence matrix of animal effect, $\mathbf{W}$ the incidence matrix of permanent environmental effect, b the vector of unknown parameters for fixed effect, $\mathbf{u}$ the vector of unknown parameters for additive genetic effect, $\mathbf{p}$ the vector of unknown parameters for permanent environmental effect, e the vector of residuals, $\mathbf{I}_{\mathbf{e}}$ the identity matrix of equal order to the number of records, $\mathbf{I}_{\mathbf{p}}$ the identity matrix of equal order to the number of sheep with milking records, A the numerator relationship matrix, $\mathbf{R}_{\mathbf{0}}$ the residual covariance matrix among the three measurements on the same animal, $\mathbf{G}_{\mathbf{0}}$ the covariance matrix for additive genetic effects, $\mathbf{P}_{\mathbf{0}}$ the covariance matrix for environmental permanent effects and $\otimes$ is the Kronecker product.

\section{Results and discussion}

Average values for MY $\mathrm{M}_{180}$, TDY and LL were, respectively, of $431.6 \mathrm{~kg}, 1660.5 \mathrm{mg}$ and 199.5 days.

The estimates of the variances, heritabilities and permanent environmental effect associated to the three analysed traits obtained using univariate models are given in Table 2, and those obtained using multivariate models are given in Tables 3 and 4. Estimates of $h^{2}$ showed similar patterns regardless the estimation model: $\mathrm{MY}_{180}$ had the highest heritability estimates $(0.131$ and 0.177 for, respectively, Models 1 and 2) while LL had the lowest; estimates of $h^{2}$ for both LL and TDY were basically the same regardless the estimation model (roughly, 5\% and $10 \%$, respectively).

This is the first time in which genetic parameters for milk production traits have been estimated for the Assaf.E population. Structure of the available data allows obtaining reliable conclusions from the analysis. The average production figures of the Assaf.E breed are substantially higher than those reported for native Spanish dairy sheep breeds; Ugarte et al. (2002) reported aver-

\section{Table 2}

Variance components and estimates of genetic parameters for lactation length in days (LL), 180 days adjusted milk production in $\mathrm{kg}\left(\mathrm{MY}_{180}\right)$ and test-day milk yield in mg (TDY) in the Assaf.E breed estimated using univariate models

\begin{tabular}{llll}
\hline & LL & MY $_{180}$ & TDY \\
\hline $\operatorname{Var}(\mathbf{u})$ & 28.54 & 1977.57 & 69339.46 \\
$\operatorname{Var}(\mathbf{c})$ & 3.69 & 3197.92 & 188383.84 \\
$\operatorname{Var}(\mathbf{e})$ & 561.86 & 9939.99 & 440187.16 \\
$\operatorname{Var}(\mathbf{p})$ & 594.09 & 15115.49 & 697910.46 \\
$h^{2}$ & $0.048(0.016)$ & $0.131(0.021)$ & $0.099(0.015)$ \\
$c^{2}$ & $0.006(0.021)$ & $0.099(0.015)$ & $0.270(0.015)$ \\
\hline
\end{tabular}


Table 3

Variance components and estimates of genetic parameters for lactation length in days (LL), 180 days adjusted milk production in $\mathrm{kg}\left(\mathrm{MY}_{180}\right)$ and test-day milk yield in mg (TDY) in the Assaf.E breed estimated using multivariate models

\begin{tabular}{lcll}
\hline & LL & MY $_{180}$ & TDY \\
\hline $\operatorname{Var}(\mathbf{u})$ & 32.61 & 2879.43 & 74074.81 \\
$\operatorname{Var}(\mathbf{c})$ & 29.46 & 6778.70 & 195857.48 \\
$\operatorname{Var}(\mathbf{e})$ & 534.56 & 6606.94 & 430359.38 \\
$\operatorname{Var}(\mathbf{p})$ & 596.6 & 16265.1 & 700290.7 \\
$h^{2}$ & 0.055 & 0.177 & 0.106 \\
$c^{2}$ & 0.049 & 0.417 & 0.280 \\
\hline
\end{tabular}

age milk yields standardised to 120 days of 119,153 and $126 \mathrm{~kg}$ for, respectively, Churra, Manchega and Latxa breeds. The Assaf.E breed has larger lactations than the native Spanish dairy sheep breeds leading to the standardisation of the total milk yield to 180 days instead of the 120 days of the native Spanish dairy sheep breeds. However, larger lactations are not the solely explanation of the higher total milk yields of the Assaf.E breed but a higher average TDY than that reported for Spanish $(0.956 \mathrm{~kg}$ for Churra breed; Othmane et al., 2002) and non-Spanish local sheep breeds (Oravcová et al., 2005). Large-persistent lactations are of major interest for Assaf.E breeders and, in fact, explain the spreading of the breed throughout Spain.

Heritabilities estimated in the present study for standardised and test-day milk yield traits are on the lower limit of those usually reported for the three analysed traits. Serrano et al. (2003) recently reported a heritability estimate of 0.18 for standardised milk yield (120 days) in Manchega ewes. However, heritability estimated for total milk yield in native Spanish dairy sheep breeds such as those of 0.23 and 0.24 for the Churra breed (ElSaied et al., 1998a; Othmane, 2000) and 0.20 and 0.21 for the Latxa breed (Ugarte et al., 1996; Legarra and Ugarte, 2001) are usually higher than those reported here

Table 4

Genetic, permanent environmental, residual and phenotypic covariances and genetic $\left(r_{\mathrm{g}}\right)$, permanent environmental $\left(r_{\mathrm{c}}\right)$ and phenotypic $\left(r_{\mathrm{p}}\right)$ correlations among lactation length (LL) in days, 180 days adjusted milk production $\left(\mathrm{MY}_{180}\right)$ in $\mathrm{kg}$ and test-day milk yield (TDY) in $\mathrm{mg}$ traits in the Assaf.E breed estimated by means of a multivariate model

\begin{tabular}{lccc}
\hline & LL-MY $_{180}$ & LL-TDY & TDY-MY $_{180}$ \\
\hline CoVar(u) & 252.65 & 1230.59 & 14581.87 \\
CoVar(c) & 416.38 & 2257.97 & 36427.02 \\
CoVar(p) & 669.84 & 3782.84 & 54356.89 \\
$r_{\mathrm{g}}$ & 0.825 & 0.792 & 0.999 \\
$r_{\mathrm{c}}$ & 0.932 & 0.940 & 0.999 \\
$r_{\mathrm{p}}$ & 0.215 & 0.185 & 0.509 \\
\hline
\end{tabular}

for the Assaf.E breed. This is also truth for the estimates of heritability for standardised milk yield reported in the literature for non-Spanish dairy sheep breeds such as Lacaune (0.30; Barillet, 1997) or Sarda (0.30; Sanna et al., 1997). However, Portolano et al. (2001), in Barbaresca siciliana sheep, reported heritability estimates for milk yield standardised to different lactation lengths that always ranged from 0.14 to 0.15 and Nikolau et al. (2004) reported different estimates for total milk yield in Lesbos dairy sheep ranging from 0.16 to 0.20 . With respect TDY, estimates of heritability are rarely reported in sheep; most of them varied from 0.14 to 0.35 (see Oravcová et al., 2005 for a review) thus being higher than those estimated here in the Assaf.E breed.

Estimates of heritability for LL are also rare in the literature varying from 0.015 in the Churra breed (ElSaied et al., 1998b) to 0.128 and 0.147 in, respectively, Improved Awassi (Pollot and Gootwine, 2001) and $B$. siciliana sheep (Portolano et al., 2001). The heritability reported by El-Saied et al. (1998b) for LL was estimated on data from a single flock; the authors concluded that most factors affecting LL are of non-genetic origin. However, the estimate by Portolano et al. (2001) was obtained on data from 44 flocks showing large phenotypic variation for LL. Our estimate of roughly $5 \%$ highlights that genetic variability for LL in the Assaf.E breed can be larger than in native Spanish dairy sheep breeds. However the dairy recording methodology used in this data set, implemented following the official Spanish rules, can have affected the estimates because larger lactations have not been fully recorded thus reducing the available variability for the trait.

The estimates of permanent environmental effect $\left(c^{2}\right)$ showed large differences with respect the estimation model except for TDY, which are consistently the same (0.27-0.28). The permanent environmental effect associated to LL estimated using Model 1 was basically 0 whilst it was of roughly a 5\% when Model 2 was used. The estimates of $c^{2}$ for MY 180 varied from 0.212 (Model 1) to 0.417 (Model 2).

These estimations of $c^{2}$ for each analysed trait showed some variation according to the estimated Model used. Although the estimates of $c^{2}$ for TDY is consistent across Models and similar to that of 0.28 reported by Baro et al. (1994) in the Churra breed, the estimates of $c^{2}$ for MY $_{180}$ and LL are substantially higher when Model 2 is used. The estimates of $c^{2}$ for $\mathrm{MY}_{180}$ are always higher than those from 0.14 to 0.15 reported for milk yield standardised to different lactation lengths in the $B$. siciliana sheep (Portolano et al., 2001). The estimate of $c^{2}$ for LL obtained using Model 1 is basically 0 whilst for that obtained using Model 2 is nearer to that of 0.03 reported 
by El-Saied et al. (1998b) in the Churra breed and quite far from that of 0.141 reported by Pollot and Gootwine (2001) in improved Awassi sheep.

Estimates of genetic correlations (Table 4) were always high ranging from 0.792 for the pair LL-TDY and 0.999 for the pair MY 180 -TDY. Correlations between permanent environmental effects were even higher ranging from 0.932 for the pair LL-MY 180 and 0.999 for the pair MY 180 -TDY.

Genetic correlation between standardised and testdays milk yield traits have not been previously reported in sheep. However, we can find high and positive estimates in dairy cattle varying from 0.76 to 1.00 (Pander et al., 1992; Ferreira et al., 2003). Published estimates of genetic correlation between LL and mil yield traits are scarce but always high and positive as those reported here for the Assaf.E breed: Portolano et al. (2001), in the B. siciliana sheep, and Pollot and Gootwine (2001), in improved Awassi sheep, reported genetic correlations between total milk yield and LL of 0.644 and 0.555 . In any case, correlations estimated between each genetic and permanent environmental effects showed that both the genes and the major environmental factors associated to the three analysed traits are the same.

An overview of the information obtained in the present study can inform of the possibilities of implementing a selection scheme for dairy traits in the Assaf.E breed. The heritabilities estimated here for the three analysed traits are low, thus limiting the possibilities of selection. Low heritabilities (in the range of those reported here the Assaf.E breed) for milk lactation traits have been reported for standardised lactation milk yield in Awassi (which is one of the parent breeds of the Assaf sheep) and Assaf in Israel (Pollot and Gootwine, 2001; Gootwine and Pollot, 2002). Pollot and Gootwine (2001) argued that the low levels of additive genetic variation and heritability for milk yield but high levels of permanent environmental effects, which may be partly due to dominance and epistatis, could reflect that the high milk production in the Israeli improved Awassi flocks can be due to non-additive genetic effects. This can be an explanation of the scenario described here for the Assaf.E breed but a less sophisticated explanation should also be considered: the dairy recording scheme of Castellana de Ganaderos has been recently founded and the available genealogies are shallow thus limiting the possibilities of a correct separation of the additive and permanent environmental effects. The low heritability estimates found in the present study may be also due to some environmental effects that were neglected in the fitted models such as the number of lambs suckled before weaning or the test-day date and its interaction with flock. Moreover, the absence of common flock-test-day environmental effect may also explain the low estimates of $c^{2}$ obtained with Model 1.

In this respect, the estimates of $c^{2}$ for TDY are more consistent than for the other traits thus suggesting that breeding values estimated for this trait can be more reliable. Jensen (2001) summarises the advantages of using test-day records instead of standardised yields for genetic evaluation in dairy programs as its higher ability to account for environmental effects of each test-day, the ability to model the trajectory of the lactation for individual genotypes or groups of animals, and the possibility of genetic evaluations for persistency of production. In the case of the Assaf.E breed in which different dairy recording schemes should be integrated to obtain national evaluations the use of TDY as selection criterion would also facilitate the analysis of information obtained in recording schemes that do not follow strictly the official Spanish recording rules (Gutiérrez and Legaz, 2004) avoiding the necessity of extending short lactations on culled animals and animals with records in progress.

\section{References}

Barillet, F., 1985. Amélioration génétique de la composition du lait des brebis. L'exemple de la RACE Lacaune. (Genetic improvement for ewe milk composition. The case of Lacaune breed.) PhD Thesis, L'institute National Agronomique, Paris-Grignon, p. 8.

Barillet, F., 1997. Genetics for milk production. In: Piper, L., Ruvinsky, A. (Eds.), The Genetics of the Sheep. CAB International.

Baro, J.A., Carriedo, J.A., San Primitivo, F., 1994. Genetic parameters of test-day measures for somatic cell count, milk yield and protein percentage of milking ewes. J. Dairy Sci. 77, 2658-2662.

El-Saied, U.M., Carriedo, J.A., San Primitivo, F., 1998a. Heritability of test day somatic cell counts and its relationship with milk yield and protein percentage in dairy ewes. J. Dairy Sci. 81, 29562961.

El-Saied, U.M., Carriedo, J.A., Baro, J.A., de la Fuente, L.F., San Primitivo, F., 1998b. Gernetic correlations and heritabilities for milk yiled and lactation lenght of dairy sheep. Small Rum. Res. 27, 217-221.

Ferreira, W.J., Teixeira, N.M., Euclydes, R.F., Verneque, R.D., Lopes, P.S., Torres, R.D., Wenceslau, A.A., da Silva, M.V.G.B., Magalhaes, M.N., 2003. Genetic evaluation of Holstein cattle using test day milk yield. Braz. J. Anim. Sci. 32, 295-303.

Goot, H., 1986. Development of Assaf, a synthetic breed of dairy sheep in Israel. In: Proceedings of the 37th Annual Meeting of the European Association for Animal Production, Budapest, pp. 1-29.

Gootwine, E., Pollot, G.E., 2002. Factors affecting the milk production of Assaf dairy sheep in Israel. In: Proceedings of the Seventh World Congress on Genetics Appl. to Livest. Prod., Montpellier, France, CD-ROM Communication No. 01-48.

Gutiérrez, J.P., Legaz, E., 2004. Influencia de efectos sistemáticos sobre la producción de leche en ovejas de raza Assaf. Mundo Ganadero 172, 43-50.

Jensen, J., 2001. Genetic evaluation of dairy cattle using test-day models. J. Dairy Sci. 84, 2803-2812. 
Jiménez, M.A., Jurado, J.J., 2005. Esquema de selección en la raza Assaf en León. ITEA 26, 99-101.

Legarra, A., Ugarte, E., 2001. Genetic parameters of milk traits in Latxa dairy sheep. Anim. Sci. 73, 407-412.

Meyer, K., 1998. bDXMRRQ - a program to estimate covariance functions for longitudinal data by restricted maximum likelihood. In: Proceedings of the Sixth World Congress, Genet. Appl. Livest. Prod., vol. 27, pp. 465-466.

Nikolau, M., Kominakis, A.P., Rogdakis, E., Zampitis, S., 2004. Effect of mean and variance heterogeneity on genetic evaluations of Lesbos dairy sheep. Livest. Prod. Sci. 88, 107-115.

Oravcová, M., Groeneveld, E., Kovac, M., Peskovicová, D., Margetín, M., 2005. Estimation of genetic and environmental parameters of milk production traits in Slovak purebred sheep using test-day model. Small Rum. Res. 56, 113-120.

Othmane, M.H., 2000. Parámetros genéticos de la composición de la leche de oveja y del rendimiento quesero en Laboratorio. PhD Thesis. Universidad de León.

Othmane, M.H., de la Fuente, L.F., Carriedo, San Primitivo, F., 2002. Heritability and genetic correlations of test day milk yield and composition, individual laboratory cheese yield, and somatic cell count for dairy ewes. J. Dairy Sci. 85, 2692-2698.

Pander, B.L., Hill, W.G., Thompson, R., 1992. Genetic parameters of test day records of British Holstein-Friesian heifers. Anim. Prod. $53,11-21$.
Pollot, G.E., Gootwine, E., 2001. A genetic analysis of complete lactation in improved Awassi sheep. Livest. Prod. Sci. 71, $37-47$.

Portolano, B., Montalbano, L., Militi, W., 2001. Genetic and environmental sources of variation for milk yiled traits in Barbaresca siciliana breed. Small Rumin. Res. 41, 195-202.

Sanna, S.R., Carta, A., Casu, S., 1997. Covariance component estimates for milk composition traits in Sarda sheep using a bivariate model. Small Rumin. Res. 25, 77-82.

Serrano, M., Pérez-Guzmán, M.D., Montoso, V., Jurado, J.J., 2003. Genetic análisis of somatic cell counts and milk traits in Manchega ewes. Mean lactation and test-day approaches. Livest. Prod. Sci. 84, 1-10.

Ugarte, E., Urarte, E., Arranz, J., Arrese, F., Rodriguez, C., Silió, L., 1996. Genetic parameters and trends for milk production of Blond-faced Latxa sheep using bayesian analysis. J. Dairy Sci. 79, 2268-2277.

Ugarte, E., Ruíz, R., Gabiña, D., Beltrán de Heredia, I., 2001. Impact of high-yielding foreign breeds on the Spanish dairy sheep industry. Livest. Prod. Sci. 71, 3-10.

Ugarte, E., Serrano, M., de la Fuente, L.F., Pérez-Guzmám, M.D., Alfonso, L., Gutiérrez, J.P., 2002. Situación actual de los programas de mejora genética en ovino de leche. ITEA 98, 102-117. 